DOI: 10.17747/TEDS-2020-33-35

Natalia Lvovna Smith ${ }^{1}$, Anton Vladimirovich Antonov ${ }^{1}$

${ }^{1}$ Department of Management, Financial University under the Government of the Russian Federation

Moscow, Russia

NLSmit@fa.ru, avantonov@fa.ru

\title{
DETERMINING THE DEGREE OF CULTURAL DISTANCE IN DIVERSITY MANAGEMENT
}

The article was prepared based on the results of research carried out at the expense of budgetary funds on the state order of the Financial University, within the framework of applied research work GZ-PI40-20 on the topic "Development of methods and mechanisms for intercultural adaptation of foreign students" determining the degree of cultural distance in diversity management.

\begin{abstract}
In the process of transforming the priority of material and technical values to the paradigm of flexible thinking, communicative interaction becomes a new value, which is a vital competence in the integrative multicultural reality of the global world, where cultural diversity is recognized as a key value. Diversity management is now dominant in organizational management, the ability to focus on organizing behavior based on the interaction of all parties in an environment where many cultures are intertwined. The multidimensionality of the multicultural environment poses a challenge in determining the degree of cultural distance in an organization. This allows us to understand the similarities and differences between the host culture and the culture of foreign visitors and students, and to identify gaps and barriers to intercultural interaction and adaptation tools. It also calls for the formation of all actors in the educational process of the necessary knowledge and skills that contribute to their adequate orientation in belonging to their own culture and awareness of the influence of their value dominants in practical situations of intercultural communication. Thus, in organizational management, host Russian universities face the challenge of recognizing their own cultural paradigm and thinking.
\end{abstract}

Keywords - diversity management, soft skills, cultural intelligence, communicative competence, paradigm of thinking, intercultural interaction, cultural adaptation

In the context of the integration of Russian universities into global education, it becomes more and more important to develop the competencies of intercultural interaction among all actors of the educational process. [1]

In the process of transformation of the material and technical values of the industrial society, the instrumental mind [2] the last century is replaced by the paradigm of flexible thinking [3]

In the process of developing internationalization, the environment of universities is constantly changing, this affects all its levels: social, informational, academic. The multidimensionality of the multicultural environment challenges educational organizations to determine the degree of cultural distance in an organization. This allows us to understand the similarities and differences between the host culture and the culture of foreign visitors and learners and to identify gaps and barriers to intercultural interaction and adaptation tools.

The ability to overcome various kinds of barriers (linguistic, psychological, sociobehavioral and others) in the process of intercultural communication is determined by the degree of differences between the subjects of interaction, which cannot be eliminated immediately in the communication process and, due to their practical significance, require special efforts and special knowledge to overcome [4]. 


\section{TYPES OF CULTURES IDENTIFIED}

Cultures can be viewed in a geographical, historical context, grouping them into different clusters [5]. In addition, according to the conclusions of G. Triandis, cultures influence selfperceptions along an independent (individualistic) and interdependent (collectivist) continuum [6].

In independent cultures, individuals can reinforce their self-image because self-sufficiency is emphasized as an individual agent [7]. People in Western cultures tend to see themselves on a fundamental level as separate and distinct from others, in the same way they perceive representatives of other cultures and expect similar identification and similar behavior from them.

Representatives of collectivist cultures demand from their carriers such a fusion with the group, in which it could be a single whole and effectively protect its members; they are more concerned with how they can benefit their social group and expect the same values from representatives of other cultures.

\section{DOMESTIC PERSPECTIVE}

This dichotomy in expectations leads to misunderstandings in the communication process. According to the study of Dervish and Gunther [8], representatives of other cultures reach mutual understanding with bearers of individualist cultures more easily than with those of collectivist ones. Individualist cultures welcome independence, they are more focused on success, selfpromotion and self-improvement [9], so representatives of such cultures are accustomed to doing as they see fit, even if their position does not coincide with the position of the group as a whole. In this regard, representatives of American, Anglo-Saxon cultures, which are typically individualistic, experience the least amount of difficulties in communicating with strangers and with foreigners, and representatives of collectivist cultures - Japanese and Koreans and representatives of other Asian cultural clusters - experience the greatest difficulties in communication and adaptation. It is important to note that for all the cultural complexity [10], in general, Russian culture largely gravitates towards the collectivist type, which means that the majority of representatives of this culture tend not to build an intercultural dialogue, but to dominate with the values of Russian culture when interacting with newcomers from abroad and representatives of other cultures. Thus, in organizational management, host Russian universities face the challenge of realizing their own cultural paradigm and paradigm of thinking.

Organizations living "within the paradigm of their own corporate culture" find it very difficult to comprehend and structure its content. In order "to understand what the sea is, the fish must see the land." Understanding and awareness of one's own paradigm can become the basis for further regulation of the issues of overcoming intercultural barriers and methods of managing diversity in the donor organization, the recipient of the subject of communication.

\section{CONCLUSION}

In this regard, it is necessary to outline the following transformations in the organizational culture of the host Russian side:

- Appeal to the knowledge of the participants about the presence of cultural differences and the possibility of their manifestation in the process of communication. In this regard, in such situations, it is required that the communication participants first of all positively perceive the very existence of barriers as such, that their overcoming is the norm of intercultural communication, and not a denial of the otherness of the interlocutor.

- Development of cultural literacy, emotional intelligence and intercultural competencies. This involves targeted training in flexible skills of all subjects of communication at all levels of the organization, both in educational and service terms. Particularly important is the systematic and regular work on the soft adaptation of foreign visitors, students, expats to the Russian cultural environment, taking into account their belonging to various cultural clusters, individualist and collectivist groups. 
- Purposeful use of cultural diversity in the educational process to ensure a greater degree of inclusiveness and as a learning resource that allows integrating the experience and knowledge of not only foreign students, but also students from different regions of the country, from different subcultural groups and social strata of society

- Formation of the necessary knowledge and skills in all actors of the educational process in order to recognize their own mental models contributing to their adequate orientation in belonging to their own culture and awareness of the influence of their value dominants in practical situations of intercultural communication. The existing knowledge in this case acquires a personal meaning, since their bearer develops a personal existential position.

- When developing a strategy for attracting and involving foreign students in the sociocultural environment of Russian universities, focus on soft power technologies and creating an enabling environment that, on the one hand, convey the values of diversity and tolerance and, on the other hand, the values of high quality and attractiveness of Russian education.

\section{REFERENCES}

[1] Prikhodko L.V., Smith N.L., Ilkevich S.V. leadership and management of change in the adaptive environment of european and russian universities p. 224 Management sciences in the modern world: corp. report scientific-practical Conf. FU .; scientific. review. magazine "Strategic decisions and risk management". 2019. - 710 s..

[2] Orekhovskaya N.A. Intercultural communication training: methodological basis and tools. // Political processes and practices. M. 2019 p. 137.

[3] Barker, J. Paradigms: The Business of Discovering the Future. Transl. from English. Moscow; 2007. 187 p.

[4] Bobrova S.P., Smirnova E.L. Fundamentals of communication theory / Textbook. allowance. - Ivanovo: Ivan. state un-t, 2005.

[5] Ten, Yu.P. (2006). Symbol in intercultural communication. Proceedings of higher educational institutions. North Caucasian region. Social Sciences, (2).

[6] Triandis, H. C. (1989). The self and social behavior in differing cultural contexts. Psychological Review, 96(3), 506-520.

[7] Heine, S. J., Lehman, D. R., Markus, H. R., \& Kitayama, S. (1999). Is there a universal need for positive self-regard?. Psychological review, 106(4), 766

[8] Darwish, Dr. Abdel Fattah \& Huber, Gunter. (2003). Individualism vs. Collectivism in Different Cultures: A cross-cultural study. Intercultural Education, 14. 47-56 ( USA). 10.1080/1467598032000044647

[9] Heine, S. J., \& Lehman, D. R. (1999). Culture, self-discrepancies, and self-satisfaction. Personality and Social Psychology Bulletin, 25, 915-925.

[10] Lebedeva N.M. An introduction to ethnic and cross-cultural psychology. - M .: Klyuch + S, 1999.S. 45. 